\title{
A utilização de artefatos de contabilidade gerencial em cooperativas agropecuárias
}

\section{The use of tools of management accounting in agricultural cooperatives}

\author{
Claudinei Isidoro \\ claudinei.isidoro@gmail.com \\ UFPR
}

Márcia Maria dos Santos Bortolocci Espejo
marciabortolocci@ ufpr.br
UFPR

\author{
Nilson Facci \\ nilsonfacci2@gmail.com \\ UFPR \\ Paulo Mello Garcias \\ paulomg@ufpr.br \\ UFPR
}

\begin{abstract}
Resumo
A reestruturação de empresas em forma de cooperativas visa a união de pessoas com o intuito de fortalecer determinada atividade comum realizada entre os cooperados. As formas de gerenciamento variam, sendo que algumas apresentam melhores desempenhos que outras. Acerca disto, este trabalho busca identificar as ferramentas gerenciais definidas pelo IFAC (1998a) que são utilizadas pelas cooperativas e se estas impactam ou não no resultado. Primeiramente emolduramos a população selecionando as cooperativas que estão entre o setor de agronegócios da Revista Exame - Melhores e Maiores de 2010. Em seguida aplicou-se questionário nas 37 cooperativas, sendo que retornaram 13 questionários válidos, os quais constituíram o banco de dados para posterior realização dos testes não-paramétricos quiquadrado e Kruskal-Wallis. Por fim, identificou-se que as cooperativas vêm utilizando artefatos de contabilidade, sendo que poucas (13\%) estão no quarto estágio. Outra descoberta foi que, dentre as cooperativas analisadas, o desempenho não depende da utilização de artefatos mais avançados de contabilidade, uma vez que os melhores desempenhos ficaram entre as empresas classificadas no terceiro estágio da contabilidade gerencial. Dentre os índices analisados individualmente, apenas o da rentabilidade sobre o patrimônio líquido foi comprovada correlação, contudo melhores índices foram encontrados nas empresas do terceiro estágio.
\end{abstract}

Palavras-chave: Contabilidade gerencial; Cooperativas; Artefatos gerenciais

\begin{abstract}
The restructuring of firms in the form of cooperatives aimed at the union of people with the aim of strengthening certain common activity carried out among members. The forms of management vary, and some have better performance than others. About this work, we seek to identify the management tools defined by the IFAC (1998a) that are used by cooperatives and whether these impact on the outcome or not. First we selected the population of the cooperatives that are among the agribusiness sector of the Revista Exame - Melhores $e$ Maiores de 2010. Then the questionnaire was applied in 37 cooperatives, and 13 returned valid questionnaires, which constituted the database for subsequent realization of testing nonparametric chi-square and Kruskal-Wallis test. Finally, we found that the cooperatives have been using accounting artifacts, and few (13\%) are in the fourth stage. Another finding was that among the cooperatives analyzed, the performance does not depend on the use of more advanced accounting artifacts, since the best performances were among the companies featured in the third stage of management accounting. Among the indexes analyzed
\end{abstract}


individually, only the return on equity was proven correlation, but higher rates were found in the third stage companies.

Keywords: Management accounting; Cooperatives; Management artifacts

Artigo recebido em: 20.04.2012; Aceito em: 21.06.2012

\section{INTRODUÇÃO}

O setor agropecuário desempenha um papel fundamental na economia brasileira. Um dos principais agentes econômicos dedicados a este setor é a cooperativa, que além da função econômica, em virtude de suas características específicas, possui também o objetivo de possibilitar o desenvolvimento social e distribuição de renda.

O crescimento da quantidade de cooperativas, além do tamanho em associados e de sua produção nos últimos anos, trouxe grandes desafios gerenciais para que as cooperativas permaneçam competitivas no mercado em que atuam. Em virtude do aumento destas entidades no cenário econômico brasileiro e em função da crescente complexidade de suas operações, vários trabalhos acadêmicos foram recentemente publicados abordando o uso das informações contábeis como ferramenta de auxilio à gestão (LIMA et al, 2001; BIALOSKORSKI NETO, 2007; ALMEIDA et al, 2009). Frezatti, Aguiar e Guerreiro (2007), discorrem, ainda mais especificamente sobre a aplicabilidade da contabilidade gerencial pelas organizações que não objetivam o lucro, pois assim como as empresas elas necessitam utilizar seus recursos de forma eficaz para atingir seus objetivos.

Com o objetivo de classificar os estágios evolutivos da contabilidade gerencial, Soutes (2006), segregou os artefatos utilizados pelas empresas no controle e gestão de seus processos, o qual possibilitou a determinação do estágio evolutivo da contabilidade gerencial de uma empresa de acordo com as ferramentas que são utilizadas.

Pelo fato das cooperativas não visarem o "lucro" propriamente dito, diversas pesquisas tiveram como finalidade definir quais os melhores indicadores para avaliar o desempenho das cooperativas agropecuárias (MENEGÁRIO, 2000; BRESSAN, BRAGA e LIMA, 2002; GRABIN, 2005; SILVA, 2005; SABADIN, 2006; GOZER et al, 2007; CARVALHO; BIALOSKORSKI NETO, 2007; PEIXE; PROTIL, 2007). Portanto, as cooperativas agropecuárias tem sido objeto de estudo de pesquisas em função do aumento da complexidade de suas operações e de sua crescente importância no mercado nacional e mundial.

Para fazer face aos desafios inerentes a este mercado, as cooperativas necessitam de ferramentas que possibilitem uma gestão eficaz. Nesta linha, o presente artigo pretende investigar a seguinte questão: em quais estágios evolutivos da contabilidade podem ser classificadas as cooperativas agropecuárias do Brasil e esta diferenciação impacta no desempenho da cooperativa? Assim, são objetivos deste estudo: (i) classificar as cooperativas agropecuárias de acordo com os estágios evolutivos da contabilidade gerencial; (ii) verificar se há relação entre o estágio da contabilidade gerencial e o desempenho; (iii) verificar se há relação entre o porte da cooperativa e o estágio da contabilidade gerencial.

Além desta introdução será discorrido sobre as características das cooperativas agropecuárias e sua importância no contexto econômico brasileiro, posteriormente, sobre os estágios da contabilidade gerencial e os seus artefatos. Na terceira parte apresenta-se a metodologia e na quarta os resultados da pesquisa, com uma detalhada análise. Por fim são apresentadas as considerações finais. 


\section{REFERENCIAL TEÓRICO}

\subsection{Cooperativas}

O cooperativismo teve seu início na cidade de Rochdale, Inglaterra, no ano de 1844, em virtude de mudanças sociais e econômicas advindas da revolução industrial. Influenciados por pensadores econômicos denominados de socialistas associacionistas, os trabalhadores de uma empresa formaram um grupo que pretendia obter independência para gerir seu próprio trabalho e renda (BIALOSKORSKI NETO, 1994). O cooperativismo, portanto, é um instrumento de que viabiliza um tipo de participação social mais efetiva de diferentes classes no processo produtivo e que também influencia na distribuição de renda (ARAÚJO, 1982). Bialoskorski Neto (2002) afirma que o cooperativismo é uma forma coletiva de organização que possibilita aos cooperados obter um poder de barganha junto ao mercado e distribuir de forma igualitária os resultados das operações. $\mathrm{O}$ autor ainda corrobora que neste formato de organização social, têm-se diferenças significativas em relação a outras empresas, pois os acionistas (cooperados) são ao mesmo tempo gestores e clientes da entidade. Desta forma não existe, em tese, a divisão entre a propriedade e controle da empresa cooperativa.

As cooperativas vêm aumentando gradativamente sua relevância na economia brasileira. Os números consolidados pela Organização das Cooperativas Brasileiras (OCB) confirmam a tendência setorial de crescimento do número de associados comparativamente ao de cooperativas. Um dado que evidencia a evolução do setor é o crescimento significativo dos números de associados (282\% de 1990 a 2008) e de empregados diretos (212\% de 1990 a 2008), vinculados ao setor cooperativista, conforme visto nas figuras 1 e 2 .

Um dos setores representativos das cooperativas é o setor agropecuário, o qual segundo a OCB (2011) é formado por 1.615 cooperativas. As cooperativas agropecuárias são essenciais para o desenvolvimento de novos projetos que possibilitam a agregação de valores sobre os produtos primários, alavancando seu valor no mercado e proporcionando um aumento da renda dos cooperados. Quando formadas essencialmente por pequenos agricultores, representam uma forma eficaz de distribuição da renda nacional. Nesta linha, Souza (2008, p. 16) corrobora a importância das cooperativas na atribuição "à função de inserção econômica dos associados junto a mercados concentrados, além de promover aumento da renda local e o desenvolvimento do agronegócio das regiões".

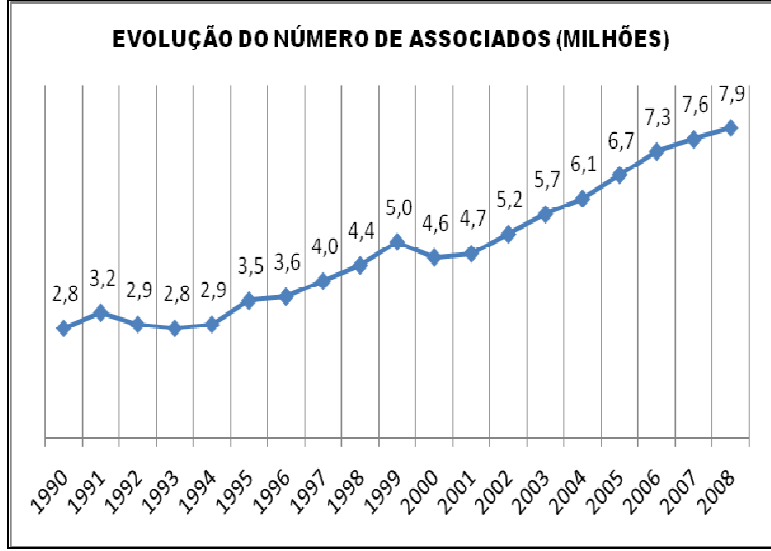

Figura 1 - Número de associados Fonte: OCB (2011)

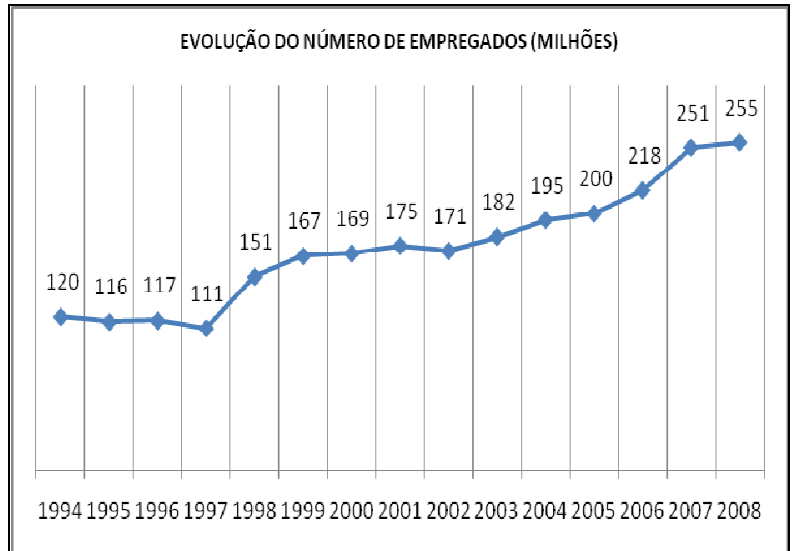

Figura 2 - Número de empregados Fonte: OCB (2011) 
Do mesmo modo de que as entidades denominadas com fins lucrativos, as cooperativas agropecuárias atuam em um mercado cada vez mais competitivo. Oliveira (2003, p. 62) elenca que as 10 principais tendências do cooperativismo são: (1) o acréscimo do nível de cooperação, (2) a ampliação e o fortalecimento da concorrência, (3) o enxugamento das estruturas, (4) a questão do tamanho ideal, (5) as fusões de cooperativas, (6) o redirecionamento da estrutura de poder, (7) a consolidação da qualidade total, (8) a aceleração da evolução tecnológica, (9) a redução do ciclo de vida dos produtos e negócios e dos desperdícios, e (10) a globalização das atividades das cooperativas. Portanto, embora as cooperativas não tenham como objetivo a obtenção de lucros, uma gestão voltada para a otimização dos recursos utilizados é fundamental para que as mesmas consigam os resultados econômicos necessários para permanecer no mercado e ao mesmo tempo atender as necessidades dos cooperados.

\subsection{Contabilidade Gerencial}

Em virtude da necessidade cada vez mais presente da tomada de decisões corretas pelos gestores das empresas e, desta forma alcançar seus objetivos, torna-se evidente, de uma forma significativa, a importância da contabilidade. E é por meio das ferramentas (artefatos) contábeis, que as informações sobre os processos internos e o ambiente externo podem ser obtidas, com características de precisão, tempestividade e veracidade que são indispensáveis para a tomada de decisões eficazes. Espejo (2009, p.12) descreve que "[...] os artefatos contábeis servem como facilitadores do alcance dos objetivos organizacionais, que a priori baseiam-se na otimização dos recursos, numa perspectiva de resultados de longo prazo [...]".

Neste contexto de crescimento da importância da contabilidade, se verificam o aumento de pesquisas que relacionam a contabilidade gerencial com a teoria de gestão e as estratégias empresariais (REIS e PEREIRA, 2007; FREZZATI, AGUIAR e GUERREIRO, 2007; MACOHON, 2009; ESPEJO et al, 2009). Esta afirmação é corroborada por pesquisas bibliométricas de trabalhos que pesquisam sobre contabilidade gerencial, divulgadas em revistas nacionais e internacionais e apresentadas nos eventos da área contábil e administrativa (HESFORD, VAN DER STEDE e YOUNG, 2007; COSTA, 2010). Dentre as temáticas mais pesquisadas referente a contabilidade gerencial, destacam-se: Sistemas de Controle Gerencial; Contabilidades de Custos; Gestão de Custos; Direcionadores de Custos; Contabilidade Gerencial, Informação e Sistemas; Métodos de Pesquisa e Teorias; Orçamento de Capital e Decisões de Investimentos. (ROCHA, ARAUJO e SILVA, 2009; CARVALHO, et al, 2010).

\subsubsection{Estágios da Contabilidade Gerencial}

Com o objetivo de delinear a área da atividade organizacional da contabilidade gerencial, em 1998 a International Federation of Accountants (IFAC), por meio do seu documento International Managemente Accounting Practice 1 (IMAP 1), identificou quatro estágios evolutivos da contabilidade gerencial ao longo dos anos, os quais se resumem no quadro 1 abaixo.

Quadro 1 - Estágios da contabilidade gerencial segundo o IMAP 1

\begin{tabular}{|c|c|l|}
\hline Estágio & Período & \multicolumn{1}{c|}{ Foco de atuação da contabilidade gerencial } \\
\hline Estágio 1 & Antes de 1950 & $\begin{array}{l}\text { Foco na determinação de custos e controle financeiro, através do } \\
\text { uso de orçamentos e tecnologias de contabilidade de custos }\end{array}$ \\
\hline
\end{tabular}

R. Cont. Ufba, Salvador-Ba, v. 6, n. 2, p. 39-55, maio-agosto 2012 


\begin{tabular}{|l|l|l|}
\hline Estágio 2 & De 1950 a 1965 & $\begin{array}{l}\text { Foco no fornecimento de informações para planejamento e } \\
\text { controle gerencial, através do uso de tecnologias, tais como } \\
\text { análise de decisão e contabilidade por responsabilidade }\end{array}$ \\
\hline Estágio 3 & De 1965 a 1985 & $\begin{array}{l}\text { Atenção na redução de desperdício dos recursos utilizados nos } \\
\text { processos da empresa, através do uso da análise de processos e } \\
\text { tecnologias de gerenciamento de custos }\end{array}$ \\
\hline Estágio 4 & De 1985 até hoje & $\begin{array}{l}\text { Atenção na geração de valor através do uso efetivo de recursos, } \\
\text { de tecnologias que examinam os direcionadores de valor para o } \\
\text { cliente e para o acionista, e de inovação organizacional }\end{array}$ \\
\hline
\end{tabular}

Fonte: adaptado de IMAP 1 (1998b), apud Beuren e Grande (2009)

O IFAC (1998a) esclarece que o deslocamento entre os quatro estágios requer um processo de mudança evolucionário. Segundo Costa (2010, p. 67) "Cada estágio evolutivo representa uma estrutura adaptativa de um novo conjunto de condições que as organizações enfrentam, absorvendo, reformando e adicionando novas tecnologias aos estágios anteriores". Portanto, isto significa uma mudança radical, embora gradual, e não superficial nos processos operacionais e de gestão das empresas.

Segundo o IFAC (1998a), o primeiro estágio, antes de 1950, teve como característica mais acentuada o foco na determinação dos custos e controle financeiro, sendo que as empresas utilizariam de uma tecnologia de produção que permitiria com facilidade a identificação dos custos de mão de obra e dos materiais utilizados. Os orçamentos e controles financeiros eram as principais ferramentas gerenciais utilizadas pelos administradores. No segundo estágio, de 1950 a 1965, os processos de tomada de decisões eram subsidiados pelo planejamento gerencial através das teorias de análise de decisão e da contabilidade por responsabilidade. Os gestores tinham como objetivo assegurar "que os recursos da empresa eram obtidos e usados com eficácia e eficiência para alcançar os objetivos da organização." (Beuren e Grande, 2009, p. 03, apud Anthony, 1965). No terceiro estágio, entre 1965 e 1985, o objetivo principal era na redução de desperdício dos recursos, utilizando projetos de melhoria da qualidade, em virtude do aumento da competição e desenvolvimento tecnológico. A visão de que a contabilidade gerencial é fundamental para o processo de gestão das empresas foi determinante para a passagem do segundo ao terceiro estágio (Beuren e Grande, 2009). No quarto estágio, a partir de 1995, verificou-se uma evolução sem precedentes da tecnologia nos processos de gestão e produção, influenciando de forma significativa as informações disponíveis para os administradores. Neste período foram desenvolvidas novas técnicas de contabilidade gerencial, tais como o balance scorecard, as medidas de valor econômico, a contabilidade estratégica.

Em 2006, Soutes procurou relacionar os artefatos que podem ser utilizados na Contabilidade Gerencial aos quatro estágio evolutivos descritos pelo IMAP 1. O quadro 2 demonstra a categorização elaborada por Soutes (2006):

Quadro 2 - Segregação dos artefatos da contabilidade gerencial

\begin{tabular}{|c|l|l|c|c|c|}
\hline \multirow{2}{*}{ Estágio } & Artefato & Código & $\begin{array}{c}\text { Métodos e } \\
\text { sistemas de } \\
\text { custeio }\end{array}$ & $\begin{array}{c}\text { Métodos de } \\
\text { mensuração e } \\
\text { avaliação de } \\
\text { desempenho }\end{array}$ & $\begin{array}{c}\text { Filosofias e } \\
\text { modelos de } \\
\text { gestão }\end{array}$ \\
\hline \multirow{2}{*}{$\mathbf{1}^{\mathbf{0}}$ estágio } & Custeio por absorção & c_abs & $\mathrm{X}$ & & \\
\cline { 2 - 7 } & Custeio Variável & c_var & $\mathrm{X}$ & & \\
\cline { 2 - 7 } $\begin{array}{c}\text { Determinação do } \\
\text { custo e controle } \\
\text { financeiro }\end{array}$ & Custeio Padrão & c_pad & $\mathrm{X}$ & & \\
\cline { 2 - 7 } & Retorno sobre o & Roir & & $\mathrm{X}$ & \\
\hline
\end{tabular}




\begin{tabular}{|c|c|c|c|c|c|}
\hline $2^{\circ}$ estágio & $\begin{array}{l}\text { Preço de } \\
\text { Transferência }\end{array}$ & p_trans & & $\mathrm{X}$ & \\
\hline \multirow{4}{*}{$\begin{array}{l}\text { Informação para } \\
\text { controle e } \\
\text { planejamento } \\
\text { gerencial }\end{array}$} & Moeda constante & m_cons & & $\mathrm{X}$ & \\
\hline & Valor presente & v_pres & & $X$ & \\
\hline & Orçamento & orc & & & $\mathrm{X}$ \\
\hline & Descentralização & desc & & & $\mathrm{X}$ \\
\hline \multirow{8}{*}{$\begin{array}{c}\mathbf{3}^{\mathbf{o}} \text { estágio } \\
\\
\text { Redução de } \\
\text { perdas de recursos } \\
\text { no processo } \\
\text { operacional }\end{array}$} & $\begin{array}{l}\text { Custeio Meta } \\
\text { (Target Costing) }\end{array}$ & c_met & $\mathrm{X}$ & & \\
\hline & $\begin{array}{l}\text { Custeio Baseado em } \\
\text { Atividades (ABC) }\end{array}$ & $a b c$ & $\mathrm{X}$ & & \\
\hline & Benchmarking & benc & & $\mathrm{X}$ & \\
\hline & Kaizen & kai & & & $\mathrm{X}$ \\
\hline & Just in Time (JIT) & jit & & & $\mathrm{X}$ \\
\hline & $\begin{array}{l}\text { Teoria das } \\
\text { Restrições }\end{array}$ & t_rest & & & $\mathrm{X}$ \\
\hline & $\begin{array}{l}\text { Planejamento } \\
\text { estratégico }\end{array}$ & p_estr & & & $\mathrm{X}$ \\
\hline & $\begin{array}{l}\text { Gestão Baseada em } \\
\text { Atividades (ABM) }\end{array}$ & $\mathrm{abm}$ & & & $\mathrm{X}$ \\
\hline \multirow{5}{*}{$\begin{array}{l}\text { Criação de valor } \\
\text { através do uso } \\
\text { efetivo dos } \\
\text { recursos }\end{array}$} & GECON & gec & & & $\mathrm{X}$ \\
\hline & Balanced Scorecard & scor & & & $\mathrm{X}$ \\
\hline & $\begin{array}{l}\text { EVA (Economic } \\
\text { Value Added) }\end{array}$ & eva & & $\mathrm{X}$ & \\
\hline & Simulação & $\operatorname{sim}$ & & & $\mathrm{X}$ \\
\hline & $\begin{array}{l}\text { Gestão Baseada em } \\
\text { Valor (VBM) }\end{array}$ & vbm & & & $\mathrm{X}$ \\
\hline
\end{tabular}

Fonte: adaptado de Soutes (2006, p. 24)

A classificação dos estágios da contabilidade gerencial de acordo com os artefatos utilizados pelas empresas contribuiu para o desenvolvimento de diversas linhas de pesquisas na área contábil (ESPEJO et al, 2009; COSTA, 2010; MACOHON, 2009). Desta forma, foi ampliado o foco para estudos que possam evidenciar a relação entre o uso da contabilidade gerencial com a gestão das organizações. Neste contexto, esta pesquisa busca identificar em qual dos estágios acima se encontram as cooperativas agrícolas do Brasil.

\subsection{Desempenho}

O estudo sobre as variáveis que influenciam na concepção de um sistema de medição de desempenho eficiente e eficaz para as empresas é um tema de crescente preocupação para os acadêmicos e profissionais (MACEDO et al, 2009, apud NEELY, 1998). Por meio das ferramentas de desempenho podem ser estabelecidos parâmetros para monitorar a gestão das empresas, avaliando e corrigindo suas ações e objetivando melhorias necessárias para alcançar as metas estabelecidas.

A análise e a mensuração de desempenho podem ser definidas literalmente como o processo de quantificar uma ação, no qual a mensuração é o processo de quantificação e a ação é aquilo que provoca o desempenho (MACEDO et al, 2009, apud NEELY, 1998). Portanto, com a coleta, classificação e interpretação dos dados é possível mensurar o desempenho e, desta forma, gerar informações necessárias para avaliar as decisões tomadas e os resultados obtidos. A mensuração do desempenho de uma empresa pode ser somente dos dados econômicos e financeiros ou considerando também informações não monetárias (HENDRIKSEN e VAN 
BREDA, 1999). Vários estudos têm contestado o uso dos indicadores contábil-financeiros como instrumento de avaliação da performance das empresas (KAPLAN e NORTON, 1997), porém também é afirmado que sozinhos eles são insuficientes mas constituem um importante parâmetro para a avaliação do desempenho organizacional (OMAKI, 2005). Como os indicadores contábil-financeiros geralmente estão mais disponíveis e acessíveis na empresa (obtidos a partir dos dados das demonstrações contábeis), se tornam mais utilizados, mesmo com a ressalva de se ter apenas uma dimensão limitada de desempenho (BRITO e VASCONCELOS, 2005). Segundo o CPC (2008), as demonstrações contábeis são preparadas e apresentadas para usuários externos em geral, tendo em vista suas finalidades distintas e necessidades diversas. As demonstrações contábeis buscam satisfazer às necessidades comuns da maioria dos seus usuários, tais como: manter ou vender um investimento em ações, avaliar a administração, etc.

As demonstrações contábeis devem ser capazes de permitir aos analistas e investidores a previsão dos fluxos de caixa dos negócios futuros das empresas, fornecendo informações úteis e compreensíveis a respeito do passado. Como as demonstrações apenas fornecem dados econômicos e financeiros é necessário transformá-los em informações. Para este processo é utilizada a análise das demonstrações contábeis. Para este fim, uma série de indicadores são calculados a partir de relações entre contas ou grupo de contas das demonstrações contábeis (MATARAZZO, 2007; ASSAF NETO, 2010)

A análise das demonstrações contábeis, por intermédio de indicadores, tem por objetivo estudar o desempenho financeiro de uma empresa em determinado momento, para diagnosticar sua posição atual e produzir resultados de tendências futuras. Os principais grupos de indicadores demonstram os aspectos financeiros, por meio dos indicadores da estrutura de capital e liquidez, e os aspectos econômicos, com os indicadores de rentabilidade (MATARAZZO, 2007; ASSAF NETO, 2010). Contudo, avaliar o desempenho é atribuir-lhe um conceito em função da comparação entre o desempenho esperado e o realizado. Por isto, os indicadores por si só não servem de parâmetro para a avaliação do desempenho, a não ser que sejam comparados com indicadores previstos ou com indicadores de outras empresas, numa pesquisa longitudinal, ou ainda, em último caso, com outros indicadores da mesma empresa, ao longo de vários períodos consecutivos (KÜHL, 2007).

Para Bialoskorki Neto (2007) uma forma de vincular os resultados às expectativas dos cooperados é estabelecer um plano estratégico com indicadores de desempenho robustos e apropriados às características de cada cooperativa. Oliveira (2003) complementa discorrendo que a participação dos cooperados na elaboração do plano estratégico da cooperativa é fundamental para que haja um interesse cada vez maior na melhoria dos processos e, conseqüentemente, consolidando o desenvolvimento da organização.

Os indicadores de desempenho e análise dos resultados das cooperativas devem ser construídos de modo estruturado, para que possam ser compreendidos e acolhidos, sobretudo pelos cooperados, executivos e funcionários da organização. Pelo fato das cooperativas terem como objetivo primário a inserção social de seus cooperados, vários estudos também tem acrescentado aos indicadores econômicos, índices que avaliam o impacto das atividades das cooperativas na sociedade em que estão inseridas (FRONZAGLIA e BIALOSKORSKI NETO, 2000; MENEGÁRIO, 2000; GRABIN, 2005; SILVA, 2005, SABADIN, 2006; GOZER et al, 2007; CARVALHO; BIALOSKORSKI NETO, 2007; PEIXE; PROTIL, 2008). Segundo Carvalho e Bialoskorski Neto (2007) os principais indicadores que avaliam o desempenho financeiro das cooperativas são a Liquidez Geral e o Endividamento e, o desempenho econômico deve ser obtido pelos índices de Margem Bruta, Margem Operacional, Margem Líquida e Retorno sobre Patrimônio (ROE). 


\subsection{Hipóteses}

Com base no referencial exposto, esta pesquisa construiu as seguintes hipóteses a serem testadas:

$\mathrm{H}_{0}=\mathrm{O}$ desempenho das Cooperativas agropecuárias independem do estágio da contabilidade gerencial onde se enquadram.

$\mathrm{H}_{1}=\mathrm{O}$ desempenho das Cooperativas agropecuárias dependem do estágio da contabilidade gerencial onde se enquadram.

\section{PROCEDIMENTOS METODOLÓGICOS}

Neste capítulo será discorrido sobre os procedimentos metodológicos utilizados para a elaboração da pesquisa. O planejamento de uma pesquisa é essencial para que se consiga obter o alinhamento necessário entre o objetivo da pesquisa, a técnica de coleta, mensuração e a análise dos dados. É também imprescindível que a pesquisa tenha uma base teórica para dar robustez aos argumentos utilizados, tanto para justificar o estudo, quanto para balizar as análises (LAKATOS; MARCONI, 1995).

Para Cooper e Schindler (2003) o planejamento de uma pesquisa tem os seguintes princípios básicos: (a) tem de ser baseado em atividade e tempo; (b) está ligado intimamente com a questão de pesquisa; (c) orienta a seleção de fontes e tipos de informações; (d) é uma estrutura para determinar as relações entre as variáveis e, (e) ressalta a conduta para cada atividade da pesquisa.

Este trabalho tem como base a teoria econômica por buscar identificar a relação entre o estágio da contabilidade gerencial e os resultados econômicos das cooperativas agropecuárias. Quanto à natureza de pesquisa, este trabalho pode ser classificado como aplicado, pois tem como consequência originar conhecimentos de aplicação prática e relacionados a uma determinada realidade. A metodologia de investigação utilizada na pesquisa foi a não experimental, pois foram analisadas, observadas e medidas todas as variáveis e comportamentos das organizações das amostragens definidas, não ocorrendo nenhuma manipulação ou controle.

A pesquisa de campo foi utilizada como instrumento para observar, por meio dos dados coletados das organizações, quais as ferramentas da contabilidade gerencial utilizadas pelas cooperativas e os dados econômicos necessários para calcular os indicadores de resultado das mesmas.

Pelo fato desta pesquisa buscar a relação dos estágios da contabilidade gerencial nas cooperativas agropecuárias ao seu desempenho, faz-se necessário utilizar um critério para identificar em que estágio está cada cooperativa. Neste sentido, será utilizado o trabalho de Soutes (2006), que relacionou o uso dos artefatos a cada estágio da contabilidade gerencial, como descrito no referencial teórico. De acordo com Martins e Theóphilo (2007, p. 60): “Os levantamentos são próprios para os casos em que o pesquisador deseja responder a questões acerca da distribuição de uma variável ou das relações entre características de pessoas ou grupos, de maneira como ocorrem em situações naturais".

A população foi direcionada às empresas relacionadas no setor de agronegócios da Revista Exame - Melhores e Maiores de 2010, e destas filtradas somente as cooperativas, compondo assim 37 amostras. Para a coleta dos dados foi aplicado um questionário, direcionado aos gerentes de contabilidade. Este questionário estava dividido em dois blocos. No Bloco 1, em questões fechadas do tipo Likert, são pesquisadas quais as ferramentas utilizadas pelas cooperativas. Foi citado cada artefato encontrado no quadro 02, e solicitado uma resposta de 1 
a 4: (1) Não usa e sem interesse em utilizar, (2) Não usa, porém gostaria de utilizar, (3) Utiliza pouco na empresa e (4) Faz parte da rotina da empresa. No Bloco 2 em questões abertas, são solicitadas informações gerais sobre as cooperativas e os respondentes. Do total de 37 questionários enviados, 13 retornaram com dados válidos.

$\mathrm{Na}$ análise, primeiramente, é realizada uma descrição do conjunto de dados obtidos, através da análise estatística descritiva, onde os dados são mensurados e, calculados suas distribuições e características de dispersão e forma. Posteriormente, a partir dos dados obtidos com as respostas do Bloco 1, é possível identificar as práticas da contabilidade gerencial utilizadas, o que permitirá classificar a contabilidade gerencial das cooperativas nos estágios descritos pelo IMAP1. Esta classificação possibilita verificar se há relação entre o estágio da contabilidade gerencial das cooperativas com o seu desempenho econômico.

Por fim, para verificar se há relação entre o estágio da contabilidade gerencial das cooperativas com os indicadores econômicos e financeiros foi utilizado o teste não paramétrico Kruskal-Wallis.

\section{RESULTADOS E DISCUSSÕES}

O link do questionário desenvolvido eletronicamente foi destinado a alta gerência contábil de cada cooperativa, cujos respondentes foram 5 contadores, 4 gerentes, 2 contabilistas, 1 supervisor e 1 analista contábil. O tempo de atuação na função do respondente se encontrou classificados em 3 respondentes com até 10 anos de experiência, 3 com 10 a 20 anos, e 7 acima de 20 anos de experiência (54\%).

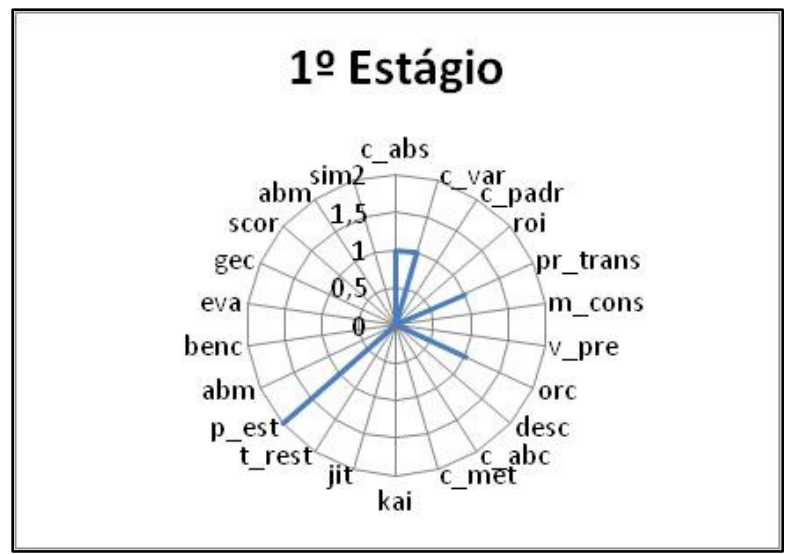

Figura 3 - Primeiro Estágio

Fonte: dados da pesquisa

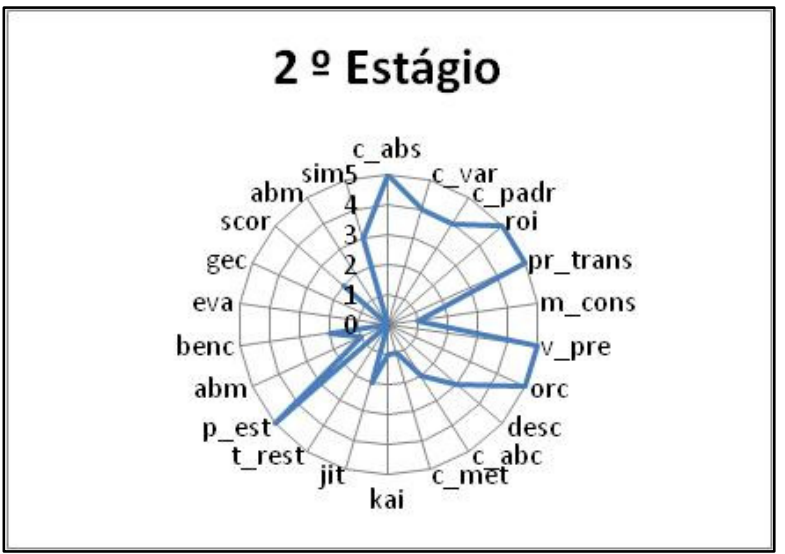

Figura 4 - Terceiro Estágio

Fonte: dados da pesquisa

A partir da estatística descritiva, os gráficos das figuras 3 a 6 mostram que é perceptível identificar que quando a cooperativa apresenta ferramentas contábeis do $4^{\circ}$ estágio, apresentam também grande percentual de ferramentas de estágios anteriores (dos estágios 1, 2 e 3), o que ocorre igualmente com os estágios 2, que mantém as ferramentas do estágio 1 , e do estágio 3 que mantém as do estágio 1e 2 respectivamente.

Os gráficos das figuras 3 a 6 também evidenciam a metodologia utilizada para classificação das cooperativas em estágios de contabilidade gerencial. Para esta classificação foi considerado o uso de pelo menos 3 práticas de contabilidade gerencial encontradas no estágio mais avançado, ou seja, acaso não apresentasse no mínimo 3 artefatos do estágio 4, verificava-se no estágio 3, se também não houvesse no mínimo 3, verificava-se o estágio 2 , assim por diante. 


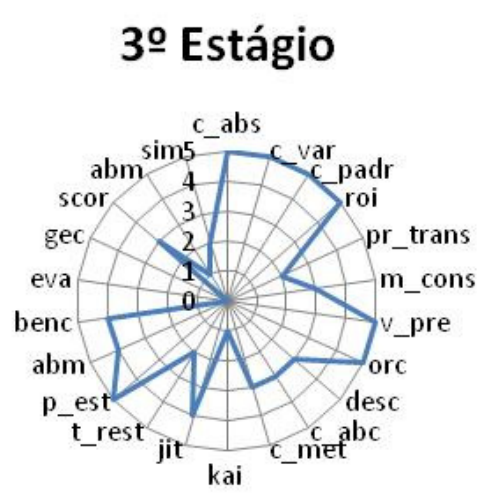

Figura 5 - Terceiro Estágio

Fonte: dados da pesquisa

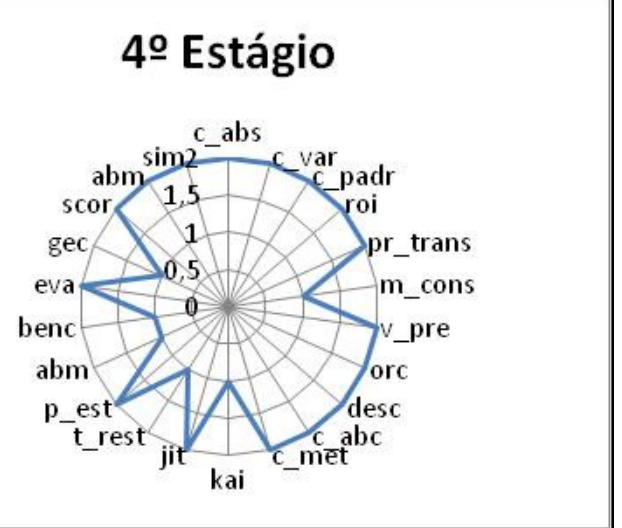

Figura 6 - Quarto Estágio

Fonte: dados da pesquisa

Isso confirma que cooperativas agropecuárias, se encontram em conformidade com os achados também de Teixeira et al (2009) em empresas, onde constatou-se que o uso das ferramentas gerenciais consideradas modernas não resultam em abandono das ferramentas tradicionais. Assim, se pode inferir uma valorização de todo o leque de ferramentas da contabilidade gerencial pelas cooperativas que se encontram no terceiro ou quarto estágio evolutivo.

Observa-se na figura 07 que a ferramenta contábil que possui mais utilização é o planejamento estratégico, por seguinte, o orçamento. E o de menos aceitação é o Gecon, o qual apenas uma das cooperativas afirmou que utiliza, mas pouco tal ferramenta. Por segundo menos utilizado foi o EVA, com apenas duas confirmações de uso.

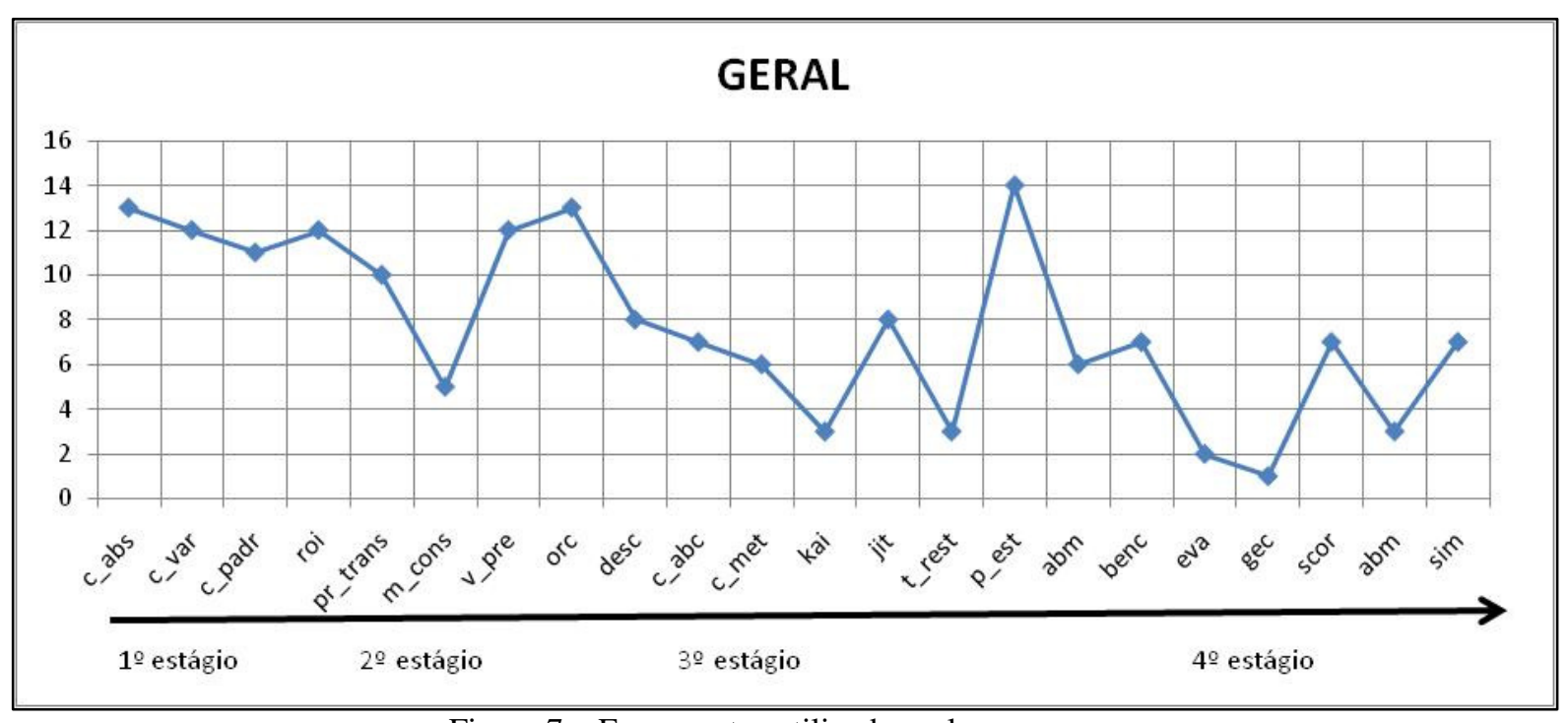

Figura 7 - Ferramentas utilizadas pelas empresas

Fonte: dados da pesquisa

A tabela 1 mostra a relação de cooperativas classificadas por estágio de contabilidade gerencial, em seguida, colunas com o ranking de cada índice de desempenho. Por ética não identificamos os valores que facilmente levariam aos respondentes, os quais mantemos o compromisso em manter em sigilo, que conforme Yin (2009) o anonimato serve para proteger seus verdadeiros participantes, uma vez que o resultado da pesquisa possa afetar ações subsequentes. Na tabela verificou-se que os 3 primeiros colocados em rentabilidade estão no 
terceiro estágio. O índice de liquidez divide o primeiro colocado e o segundo com empresas do estágio 1 e 3 . Os melhores índices de margem líquida ficou concentrada no estágio 3 , em seguida tem-se os índices de endividamento, número de funcionários e número de cooperados dividindo posições entre o estágio 1 e 4 . Os dois melhores índice de vendas prevaleceram no estágio 4. Nenhuma das 3 primeiras posições de desempenho foram encontradas no estágio 2.

Tabela 1 - Ranking de desempenho

\begin{tabular}{|c|c|c|c|c|c|c|c|c|}
\hline $\begin{array}{l}\text { Enquadramento } \\
\text { no estágio }\end{array}$ & Cooperativa & RENT PL & LIQ GER & MG LIQ & ENDIV & VENDAS & N. FUNC & N.COOP \\
\hline \multirow{2}{*}{ Estágio 1} & Cooperativa 01 & $05^{\circ}$ & $01 .^{\circ}$ & $09 .^{\circ}$ & $03 .^{\circ}$ & $12 .{ }^{\circ}$ & $13 .^{\circ}$ & $09 . .^{\circ}$ \\
\hline & Cooperativa 02 & $08 .^{\circ}$ & $08 .^{\circ}$ & $04 .^{\circ}$ & $02 .^{\circ}$ & $03 .{ }^{\circ}$ & $02 .^{\circ}$ & $01^{\circ}$ \\
\hline \multirow{5}{*}{ Estágio 2} & Cooperativa 03 & $13 .^{\circ}$ & $13 .^{\circ}$ & $12 .^{\circ}$ & $11 .^{\circ}$ & $04 .^{\circ}$ & $04^{\circ}$ & $11 .^{\circ}$ \\
\hline & Cooperativa 04 & $10 .^{\circ}$ & $11 .^{\circ}$ & $11^{\circ}$ & $10 .^{\circ}$ & $11 .^{\circ}$ & $10^{\circ}$ & $07 .^{\circ}$ \\
\hline & Cooperativa 05 & $06 .^{\circ}$ & $03 .{ }^{\circ}$ & $06 .^{\circ}$ & $08 .{ }^{\circ}$ & $07 .^{\circ}$ & $11 .^{\circ}$ & $12 .{ }^{\circ}$ \\
\hline & Cooperativa 06 & $11 .^{\circ}$ & $12 .^{\circ}$ & $10 .^{\circ}$ & $07 .^{\circ}$ & $13 .^{\circ}$ & $06 .^{\circ}$ & $10 .^{\circ}$ \\
\hline & Cooperativa 04 & $12 .^{\circ}$ & $10 .^{\circ}$ & $13 .^{\circ}$ & $05 .^{\circ}$ & $09 .^{\circ}$ & $08^{\circ}$ & $13 .^{\circ}$ \\
\hline \multirow{4}{*}{ Estágio 3} & Cooperativa 07 & $01 .^{\circ}$ & $05 .^{\circ}$ & $02 .^{\circ}$ & $13 .^{\circ}$ & $05 .^{\circ}$ & $09 .{ }^{\circ}$ & $08 .^{\circ}$ \\
\hline & Cooperativa 09 & $03 .{ }^{\circ}$ & $07 . .^{\circ}$ & $07 .^{\circ}$ & $12 .^{\circ}$ & $10 .^{\circ}$ & $07 .^{\circ}$ & $03 .^{\circ}$ \\
\hline & Cooperativa 10 & $02 .^{\circ}$ & $02 .^{\circ}$ & $01 .^{\circ}$ & $06 .^{\circ}$ & $06 .^{\circ}$ & $12^{\circ}$ & $06 .^{\circ}$ \\
\hline & Cooperativa 11 & $04 .^{\circ}$ & $06 .^{\circ}$ & $05 .^{\circ}$ & $04 .^{\circ}$ & $08 .{ }^{\circ}$ & $05^{\circ}$ & $05 .^{\circ}$ \\
\hline \multirow{2}{*}{ Estágio 4} & Cooperativa 12 & $09 .^{\circ}$ & $09 .^{\circ}$ & $08 .^{\circ}$ & $09 .{ }^{\circ}$ & $01 .^{\circ}$ & $01 .^{\circ}$ & $02 .^{\circ}$ \\
\hline & Cooperativa 13 & $07 .^{\circ}$ & $04 .^{\circ}$ & $03 .{ }^{\circ}$ & $01 .^{\circ}$ & $02 .^{\circ}$ & $03 .{ }^{\circ}$ & $04 .^{\circ}$ \\
\hline
\end{tabular}

Fonte: dados da pesquisa

Para maior qualidade da pesquisa, realizou-se o teste não-paramétrico qui-quadrado de ajustamento (goodness of fit) da amostra, explorando a proporção da variável "vendas", o qual o $p$ value resultou em 0,819 , ou seja, a amostra estudada representa a população selecionada na categoria de vendas:

Tabela 2 - Resultado do teste de Qui-quadrado de ajustamento

\begin{tabular}{|c|c|c|c|c|}
\hline Faixa & Vendas & Observações & Expectativa & Residual \\
\hline 1 & $\mathrm{R} \$ 0$ a $\mathrm{R} \$ 500$ milhões & 10 & 9,6 & 0,4 \\
\hline 2 & $R \$ 500$ milhões a $R \$ 1$ bilhão & 2 & 2,7 & $-0,7$ \\
\hline 3 & Maior que $\mathrm{R} \$ 1$ bilhão & 1 & 0,7 & 0,4 \\
\hline \multicolumn{2}{|r|}{ Total } & 13 & \multirow{2}{*}{\multicolumn{2}{|c|}{ valor-p: 0,819 }} \\
\hline Qui & drado: 0,399 & iberdade: 2 & & \\
\hline
\end{tabular}

Fonte: dados da pesquisa

Uma vez classificada e mapeada as cooperativas nos estágios de contabilidade gerencial, buscou-se identificar estatisticamente se as cooperativas do último estágio teriam ou não melhores desempenho que as demais. Assim por meio do SSPS (Statistical Package for Social Sciences) foi calculado o teste de médias Kruskal-Wallis, o qual apresentou o ranquiamento de todas as variáveis (índices financeiros) conforme a tabela 3.

Tabela 3 - Ranking do Teste de Kruskal-Wallis

\begin{tabular}{c|r|r|r|r|r|r|r}
\hline $\begin{array}{c}\text { Ranking nos } \\
\text { Estágio }\end{array}$ & Rentabilidade & Margem & Liquidez & Endividamento & Vendas & Funcionários & Cooperados \\
\hline Estagio 1 & 7,50 & 7,50 & 9,25 & 2,50 & 6,50 & 6,50 & 8,50 \\
\hline Estagio 2 & 3,6 & 3,60 & 4,60 & 8,20 & 5,20 & 6,20 & 3,80 \\
\hline
\end{tabular}




\begin{tabular}{l|r|r|r|r|r|r|r}
\hline Estagio 3 & 11,50 & 10,13 & 8,50 & 8,75 & 6,75 & 5,75 & 8,25 \\
\hline Estagio 4 & 6,00 & 8,75 & 7,75 & 5,00 & 12,50 & 12,00 & 11,00 \\
\hline
\end{tabular}

Fonte: dados da pesquisa

Ao analisar o resultado do teste Kruskal-Wallis na tabela 4 verificou-se que apenas o índice de rentabilidade apresenta correlação com os estágios, cujo $p$-value de 0,025 foi inferior a 0,05 de significância, sendo que para os valores encontrados para a margem, liquidez, endividamento e vendas mostram que não existe diferença significativa entre os estágios de contabilidade gerencial, ou seja, não há como confirmar que ferramentas mais modernas de contabilidade gerencial trazem necessariamente melhor desempenho, aceitando assim a $\mathrm{H}_{0} \mathrm{e}$ refutando a $\mathrm{H}_{1}$.

Uma vez encontrado associação apenas para o de rentabilidade voltou-se a tabela 3 e verificou-se o ranking deste índice, o qual apresentou maior valor $(11,50)$ para o terceiro estágio, ou seja, nem sempre, cooperativas em estágios de contabilidade gerencial mais avançadas, apresentam melhor desempenho.

Tabela 4 - Resultado do Teste de Kruskal-Wallis - (variável por Estágio)

\begin{tabular}{l|r|r|r|r|r|r|r}
\hline $\begin{array}{l}\text { Informações } \\
\text { do Teste }\end{array}$ & Rentabilidade & Margem & Liquidez & Endividamento & Vendas & Funcionários & Cooperados \\
\hline Qui-quadrado & 9,316 & 6,842 & 3,354 & 4,480 & 5,107 & 3,953 & 7,503 \\
\hline $\begin{array}{l}\text { Graus de } \\
\text { Liberdade }\end{array}$ & 3 & 3 & 3 & 3 & 3 & 3 & 3 \\
\hline$p$-value & 0,025 & 0,077 & 0,340 & 0,214 & 0,164 & 0,267 & 0,057 \\
\hline
\end{tabular}

Fonte: dados da pesquisa

Novamente, estes achados corroboram em parte com os resultados da pesquisa de Teixeira et al. (2009), que concluíram que não há evidencias empíricas da relação entre o grau de utilização de ferramentas tradicionais e modernas de contabilidade gerencial e o desempenho econômico das empresas, e com esta pesquisa, também das cooperativas agropecuárias.

Ainda na tabela 4, é demonstrado que, além dos índices financeiros, a quantidade de funcionários ou de cooperados, também não influencia no uso de artefatos mais modernos de contabilidade ou no desempenho.

\section{CONSIDERAÇÕES FINAIS}

A primeira parte da pesquisa identificou que grande parte das cooperativas vem utilizando diferentes ferramentas de contabilidade gerencial, principalmente planejamento estratégico e orçamento, embora algumas como o Gecon e EVA ainda estão longe da aplicabilidade na prática. Dentre as cooperativas analisadas, verificou-se que apresentam concentração entre o segundo e o terceiro estágio, com 5 e 4 cooperativas respectivamente. Os estágios 1 e 4 apresentaram apenas duas cooperativas cada, ou seja o enfoque dado ainda é a de fornecimento de informações para o controle e planejamento gerencial com atenção para redução de custos e perdas nos processos operacionais.

Embora o retorno das respostas ficasse em 35\%, o teste não-paramétrico de qui-quadrado de ajustamento (goodness of fit) realizado na população garantiu a generalização da amostra para toda a população a qual foi emoldurada: cooperativas de agronegócios cujo desempenho destacaram-na na Revista Exame - Melhores e Maiores de 2010.

Por seguinte o teste de Kruskal-Wallis evidenciou que não há correlação entre os principais indicadores financeiros demonstrados no referencial teórico, cujo perfazem as variáveis: margem, liquidez, endividamento, vendas, número de funcionários e cooperados com os 
quatro estágios evolutivos da contabilidade gerencial. Apenas o de rentabilidade foi aceito, contudo com maiores valores no terceiro, e não quarto estágio, como se poderia inicialmente imaginar. Contudo, a hipótese nula de que 'O desempenho das Cooperativas agropecuárias independem do estágio da contabilidade gerencial onde se enquadram' foi aceita, isso demostra que melhores e mais atualizadas ferramentas não garantem maior lucratividade, uma vez que as cooperativas enquadradas no terceiro estágio é que tiveram maior lucro.

Por fim, as limitações a considerar, é que os resultados encontrados nesta pesquisa limitam-se as cooperativas, cujo perfazem a moldura populacional deste trabalho. Para futuras pesquisas propõem-se as seguintes investigações: estender o presente estudo para outros ramos de atividade de modo detalhado, e verificar como a contabilidade, por meio de suas informações participa no processo de desempenho.

\section{REFERÊNCIAS}

ALMEIDA, L. B. de; MACHADO, E. A.; RAIFUR, Léo, NOGUEIRA, D. R.. A Utilização do Orçamento como Ferramenta de Apoio à Formulação de Estratégia, de Controle e de interatividade: Um Estudo Exploratório nas Cooperativas Agropecuárias da Região Sul do Brasil. Revista Contabilidade Vista \& Revista, UFMG, Belo Horizonte, v. 20, n. 3, p. 6599, jul/set 2009.

ARAÚJO, S.M.P. de. Eles: A Cooperativa; Um estudo sobre a ideologia da participação. Curitiba: Projeto, 1982.

ASSAF NETO, A. Estrutura e análise de balanços: um enfoque econômico-financeiro. 9. ed. São Paulo: Atlas, 2010.

BEUREN, I. M.; GRANDE, J. F. . Mudanças de práticas de contabilidade gerencial identificadas com aplicações da análise de discurso crítica no RA de empresa. Anais do Congresso da Associação Nacional dos Programas de Pós-Graduação em Ciências Contábeis, São Paulo, SP, Brasil, 3. 2009. CD-ROM.

BIALOSKORSKI NETO, S. Agribusiness cooperativo: economia, doutrina e estratégias de gestão. Dissertação (Mestrado). Escola Superior de Agricultura "Luiz de Queiros", Universidade de São Paulo. Piracicaba, 1994.

Estratégias e cooperativas agropecuárias: um ensaio analítico. In: Agronegócio cooperativo - reestruturação e estratégias. Marcelo José Braga, Brício dos Santos Reis (org). Viçosa, 2002.

Um ensaio sobre desempenho econômico e participação em cooperativas agropecuárias. Revista de Economia e Sociologia Rural, Rio de janeiro, vol. 45, n. 01. P. 199-138, jan/mar 2007.

BRESSAN, V. G. F.; BRAGA, M. J.; LIMA, J. E. de.. Avaliação de estratégias financeiras das cooperativas de cafeicultores do estado de Minas Gerais. Revista de Economia e Sociologia Rural. V. 40, n. 4, Brasília. Out./dez. 2002. 
BRITO, L. A. L.; VASCONCELOS, F. C. A Influência do País de Origem no Desempenho das Empresas. Revista de Administração Contemporânea - RAC. v. 9, n. 4, p. 97-118, 2005.

CARVALHO, F. L.: BIALOSKORSKI NETO, S. Identificação dos Principais Indicadores para Avaliação de Desempenho Financeiro de Cooperativas Agropecuárias. Londrina, 22 a 25 de julho de 2007, Sociedade Brasileira de Economia, Administração e Sociologia Rural, Brasil, 2007.

CARVALHO, K. L.; SARAIVA JR. A. F.; FREZATTI, F.; COSTA, R. P.. A contribuição das teorias do ciclo de vida organizacional para a pesquisa em contabilidade gerencial. RAM, Revista de Administração Mackenzie (Online) vol.11 no.4 São Paulo Jul/Ago. 2010

CPC, COMITE DE PRONUNCIAMENTOS CONTABEIS. Pronunciamento Conceitual

Básico. Disponível em: <http://www.cpc.org.br/pdf/pronunciamento_conceitual.pdf > Acesso em: 19 abr. 2011.

COOPER, Donald R.; SCHINDLER, Pamela S. Métodos de pesquisa em administração. 7 ed. - Porto Alegre: Bookman, 2003

COSTA, Flaviano. A Produção do Saber nos Campos de Controladoria e Contabilidade Gerencial: Uma Análise Da Produção Científica Inspirada Na Arqueologia

Foucaultiana. 2010 Dissertação (Mestrado em Ciências Contábeis) - Universidade Federal do Paraná, Curitiba, Paraná, 2010.

ESPEJO, M. M. S. B. E., COSTA, Flaviano, CRUZ, Ana Paula C. da, ALMEIDA, Lauro Brito de. Uma Análise Crítico-Reflexiva da Compreensão da Adoção dos Artefatos de Contabilidade Gerencial sob uma Lente Alternativa - A Contribuição de Abordagens Organizacionais. RCO - Revista de Contabilidade e Organizações - FEARP/USP, v. 3, n. 5, p. 25 - 43 jan./abr. 2009.

FREZATTI, F., AGUIAR, A. B. de, GUERREIRO, R. Diferenciações entre a Contabilidade Financeira e a Contabilidade Gerencial: Uma Pesquisa Empírica a partir de Pesquisadores de Vários Países. Revista Contabilidade e Finanças - USP, São Paulo, n. 44, p. 9 - 22, Maio/Agosto 2007.

FRONZAGLIA, T. e BIALOSKORSKI NETO, S. Equity management and property rights on cooperatives: Comparison between United States and Brazil strategies. Anais X World Congress of Rural Sociology e XXXVIII Congresso Brasileiro de Economia e Sociologia Rural. Rio de Janeiro. Brasília, SOBER. 2000.

GOZER, I. C.: GIMENES, R. M. T.: MENEZES, E. A.: GOZER, D F.; GIMENES, F. M. P. Avaliação Econômico-Financeiro de Cooperativas Agropecuárias Utilizando Índices-Padrão do Setor: um Estudo de Caso. XLV CONGRESSO DA SOBER, Anais “Conhecimento para Agricultura do Futuro", Londrina, PR, 22 a 25 de julho de 2007. 
GRABIN Raquel. Avaliação dos Resultados dos Modelos Fleuriet e EVA em Cooperativas Agropecuárias do Estado do Rio Grande do Sul. Dissertação (Mestrado) Universidade Federal de Santa Maria (UFSM), RS, 2005.

HENDRIKSEN, E. S.; VAN BREDA, M. F. Teoria da Contabilidade. São Paulo: Atlas, 1999.

HESFORD, J. W., LEE, S., VAN Der STEDE, W. A., YOUNG, M. S. Management accounting: a bibliographic study. In C. S. Chapman, A. G. Hopwood, \& M. D. Shields (Orgs.), Handbook of management accounting research (Cap. 1, Vol. 1, pp. 1-26). Amsterdam: Elsevier. (2007).

IFAC, INTERNATIONAL FEDERATION OF ACCOUNTANTS. International Management Accounting Practice Statement: Management Accounting Concepts. New York, 1998a.

International Management Accounting Practice 1 (IMAP1), March, 1998b.

KAPLAN, S R. NORTON P. D. A estratégia em ação: balanced scorecard. 4 ed. Rio de Janeiro: Campus, p.344, 1997.

KÜHL, Marcos Roberto O Mercado de Capitais reflete nos preços das ações o desempenho empresarial medido por indicadores contábeis? Dissertação (Mestrado em Contabilidade) - Universidade Federal do Paraná. Curitiba, Paraná, 2007.

LAKATOS, Eva Maria; MARCONI, Marina de Andrade. Metodologia do trabalho científico. São Paulo: Atlas, 1995.

LIMA, J. B.; SANTOS, A. C.; PILA, M. E. Z.; RODRIGUES, V.. Práticas modernas de gestão e gestão moderna em cooperativas. In: IV Congresso Brasileiro de Administração Rural, 2001, Goiânia. Anais do IV Congresso Brasileiro de Administração Rural. Lavras: Editora da UFLA, 2001.

MACEDO, Marcelo A.S.; CORRAR, Luiz J.; SIQUEIRA, José R. M. Análise comparativa do desempenho contábil-financeiro de Empresas sócio-ambientalmente responsáveis no Brasil., ANPCONT, 2009.

MACOHON; Edson Roberto. Reflexos da Institucionalização de Hábitos e Rotinas Organizacionais nos Estágios Evolutivos da Contabilidade Gerencial. Dissertação (Mestrado). Centro de Ciências Sociais Aplicadas da Universidade Regional de Blumenau, Blumenau, 2009.

MARTINS, Gilberto de Andrade; THEÓPHILO, Carlos Renato. Metodologia da investigação científica para ciências sociais aplicadas. São Paulo: Atlas: 2007.

MATARAZZO, Dante Carmine. Análise Financeira de Balanços - Abordagem Básica e Conceitual. São Paulo: Atlas: 2007. 
MENEGÁRIO, A. H. Emprego de indicadores sócio-econômico na avaliação financeira de cooperativas agropecuárias. Dissertação (Mestrado) - Escola Superior de Agricultura "Luiz de Queiroz", Universidade de São Paulo, Piracicaba, 2000.

NEELY, A. Measuring business performance. London: The Economist Books, 1998.

OLIVEIRA, Djalma de Pinho Rebouças de. Manual de Gestão das Cooperativas: Uma Abordagem Prática. 2. Ed. São Paulo. Atlas, 2003.

OMAKI, E. T. Recursos Intangíveis e Desempenho em Grandes Empresas Brasileiras: avaliações dos recursos intangíveis como estimadores de medidas de desempenho financeiras. In: ENCONTRO DA ASSOCIAÇÃO NACIONAL DE PÓS-GRADUAÇÃO E PESQUISA EM ADMINISTRAÇÃO, 29., 2005, Brasília. Anais do XXIX ENANPAD. Brasília: ANPAD, 2005. CD-ROM.

OCB - ORGANIZAÇÃO DAS COOPERATIVAS BRASILEIAS. Cooperativismo: Forma ideal de organização. Disponível em http://www.ocb.org.br/site/cooperativismo. Acessado em 10 de novembro de 2010.

PEIXE, J. B.; PROTIL, R. M. Eficiência Econômica e Social das Cooperativas Agroindustriais Paranaenses: Proposta de um Modelo de Avaliação. Informe Gepec - Vol. 12, n. 2, jul/dez. 2007.

REIS, L. G. dos; PEREIRA, C. A.; Uma Análise das Contribuições das Teorias Organizacionais para o Estudo da Contabilidade Gerencial, Congresso USP, 2007.

ROCHA, A. M.; ARAÚJO, E. A. T.; SILVA, W. A. C.. A Contabilidade Gerencial nos Eventos EnAnpads de 2004 a 2008. ABCustos Associação Brasileira de Custos - Vol. IV n ${ }^{\circ}$ 1 - jan/abr 2009.

SABADIN, Anderson Léo. Análise de Indicadores Contábeis para Avaliação de Desempenho Favorável - Um Estudo nas Cooperativas do Estado do Paraná. Dissertação (mestrado) Universidade Regional de Blumenau, SC, 2006.

SILVA, Emanuel Sampaio A EFICIÊNCIA ECONÔMICA E SOCIAL EM COOPERATIVAS DO SETOR PECUÁRIO EM PERNAMBUCO. Custos e agronegócio on line - v. 1, n. 2 - Jul/Dez - 2005.

SOUTES, D. O. Uma investigação do uso de artefatos da contabilidade gerencial por empresas brasileiras. Dissertação (Mestrado) - FEA/USP, São Paulo, 2006.

SOUZA, Uemerson Rodrigues. Eficiência técnica e de escala das cooperativas agropecuárias do estado do Paraná. Dissertação (mestrado). Universidade Federal de Viçosa, MG, 2008.

TEIXEIRA, A. J. C.; GONZAGA, R. P.; SANTOS, A. V. S. M., NOSSA, V. A utilização de ferramentas de contabilidade gerencial nas empresas do estado do Espírito Santo, III CONGRESSO IAAER-ANPCONT. Anais. São Paulo, 2009. 
YIN, Robert K. Case study research: design and methods. 4th ed. Sage Publications, Inc. 2009. 